\title{
Identifying the optimal criteria of radiotherapeutic parameters for patients with unresectable locally advanced hepatocellular carcinoma
}

\author{
Seok Hyun Son ${ }^{1}$, Hong Seok Jang ${ }^{2}$, Soo Yoon Sung ${ }^{1}$, Hye Jin Kang ${ }^{1}$, Sojung Lee ${ }^{1}$, \\ Chul Seung Kay ${ }^{1}$ \\ ${ }^{1}$ Department of Radiation Oncology, Incheon St. Mary's Hospital, College of Medicine, The Catholic University of Korea, \\ Seoul, Korea \\ ${ }^{2}$ Department of Radiation Oncology, Seoul St. Mary's Hospital, College of Medicine, The Catholic University of Korea, Seoul, \\ Korea \\ Correspondence to: \\ Chul Seung Kay, e-mail: k41645@chol.com \\ Keywords: hepatocellular carcinoma, radiotherapy, optimal criteria, radiotherapeutic parameters \\ Received: July 30, $2015 \quad$ Accepted: October 05, $2015 \quad$ Published: October 16, 2015
}

\section{ABSTRACT}

The purpose of this study is to identify the optimal criteria of the radiotherapeutic parameters in patients with unresectable locally advanced hepatocellular carcinoma (HCC). 103 patients were enrolled in this study. All patients received RT delivered using the TomoTherapy Hi-Art system between March 2006 and February 2012. We evaluated the planning target volume (PTV), total dose $\left(\mathrm{Gy}_{10}\right)$, and NTNL-V $\mathrm{BED}_{\mathrm{B} 20}$ (non-target normal liver volume receiving more than a biologically effective dose of $20 \mathrm{~Gy}_{8}$ ) as significant radiotherapeutic parameters associated with hepatic function deterioration and local progression-free survival (PFS). A PTV of $279 \mathrm{~cm}^{3}$ or $304 \mathrm{~cm}^{3}$, a total dose of $60 \mathrm{~Gy}_{10}$, and a NTNL- $\mathrm{V}_{\text {BED20 }}$ of $40.8 \%$ were identified as the optimal cutoff values of radiotherapeutic parameters to prevent hepatic function deterioration and prolong local PFS. Based on these findings, patients were divided in a favorable and an unfavorable prognosis group. The differences in median local PFS, overall survival, and incidence of deteriorated hepatic function between the two groups were 11.2 months, 11.1 months, and $71.7 \%$, respectively $(p<0.001$ in each case). In conclusion, we suggest that the optimal criteria of the radiotherapeutic parameters for patients with unresectable locally advanced HCC are: PTV $\leq 279 \mathrm{~cm}^{3}$, total dose $>60 \mathrm{~Gy}_{10}$, and NTNL-V $\mathrm{BED} 20 \leq 40.8 \%$.

\section{INTRODUCTION}

The standard treatments for unresectable hepatocellular carcinoma (HCC) are transarterial chemoembolization (TACE) and sorafenib. TACE is currently recommended for large multinodular HCC, while sorafenib is the suggested first-line of treatment for HCC with vascular invasion or extrahepatic spread. There is now strong evidence that TACE enhances the survival of patients with unresectable locally advanced HCC $[1,2]$. However, large tumors have an arterial and portal blood supply, and hence, they might remain viable after TACE and give rise to recurrence or metastasis [3]. Radiotherapy (RT) in addition to TACE could overcome these limitations and improve clinical outcomes [4-9]. Although the Sorafenib Hepatocellular Carcinoma Assessment Randomized Protocol and the Asia-Pacific trial found that the sorafenib improved overall survival compared with placebo, the survival benefit was modest $[10,11]$. In addition, many studies have suggested RT as an effective treatment option for patients with unresectable locally advanced HCC $[12,13]$. A new strategy including $\mathrm{RT}$ is therefore needed in the treatment of unresectable locally advanced HCC.

However, to date, there are no clear guidelines as to when and how it should best be used. In this study, we have evaluated the clinical outcomes of RT in patients with unresectable locally advanced HCC and have identified 
the optimal criteria of the radiotherapeutic parameters for its use.

\section{RESULTS}

\section{Response, survival and hepatic function deterioration}

The median follow-up duration was 11.6 months (range: $3.5-85.3$ months), and 13 patients (12.6\%) were alive at the time of analysis. Complete or partial response were achieved in 58 of 103 patients $(56.3 \%)$, while stable or progressive disease were observed in 45 of 103 patients $(43.7 \%)$. The median local progression-free survival (PFS) duration was 9.0 months, and the 1-year and 2-year local PFS rates were $41.5 \%$ and $16.5 \%$, respectively. The median overall PFS duration was 6.4 months, and the 1-year and 2-year overall PFS rates were $26.9 \%$ and $10.8 \%$, respectively. The median overall survival (OS) duration was 11.6 months, and the 1-year and 2-year OS rates were 48.5\% and $23.4 \%$, respectively. Hepatic function deterioration occurred in 47 patients $(45.6 \%)$.

\section{Identifying cut-off values of radiotherapeutic parameters associated with hepatic function deterioration and local PFS}

Based on a maximally selected chi-square test, a planning target volume (PTV) of $279 \mathrm{~cm}^{3}$ and a non-target normal liver (NTNL)- $\mathrm{V}_{\text {BED20 }}$ of $40.8 \%$ were found to be

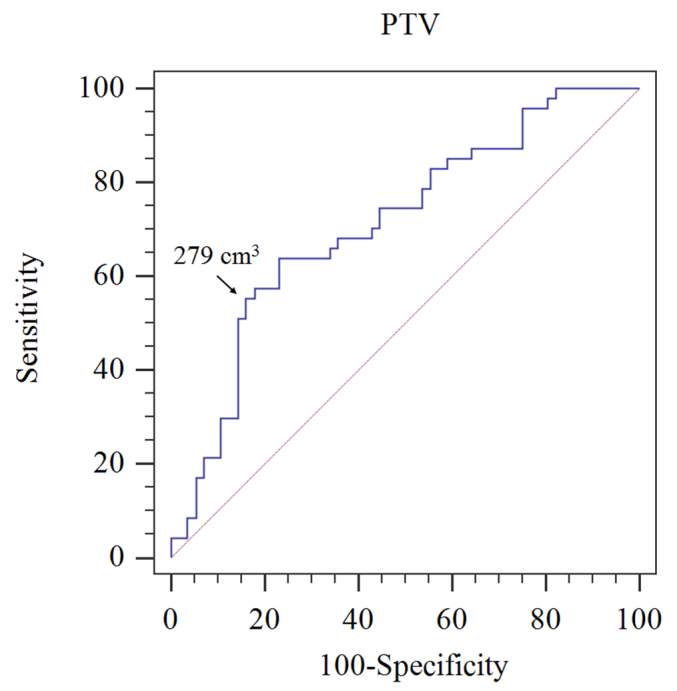

(A) significantly associated with hepatic function deterioration. These cut-off values were re-evaluated by using a receiver operating characteristics (ROC) curve. For PTV, the sensitivity was 0.553 and the specificity was 0.839 , with an area under the curve (AUC) of $0.712(p<0.001)$. For NTNL- $\mathrm{V}_{\text {BED20 }}$, the sensitivity was 0.830 and the specificity was 0.732 , with an AUC of $0.817(p<0.001)$ (Figure 1). The total dose $\left(\mathrm{Gy}_{10}\right)$ was not significantly associated with hepatic function deterioration $(p=0.056)$.

Based on a maximally selected log-rank test, a PTV of $304 \mathrm{~cm}^{3}$ and a total dose of $60 \mathrm{~Gy}_{10}$ were also found to be significantly associated with local PFS, and these cutoff values were re-evaluated by using the Cox regression model (PTV of $304 \mathrm{~cm}^{3}: \mathrm{HR}=2.092, \mathrm{CI}=1.353-3.234$, $p=0.002$; total dose of $60 \mathrm{~Gy}_{10}: \mathrm{HR}=1.824, \mathrm{CI}=1.116$ $2.979, p=0.017)$ and Kaplan-Meier survival analysis $(p<0.001$ and 0.015 , respectively) (Figure 2).

\section{Identifying the optimal criteria of radiotherapeutic parameters}

Patients were divided in four groups (group 1, 2, 3, and 4) based on a PTV of $279 \mathrm{~cm}^{3}$ and a NTNL$\mathrm{V}_{\mathrm{BED} 20}$ of $40.8 \%$, which were identified as cut-off values of significant radiotherapeutic parameters associated with hepatic function deterioration. Table 1(A) shows local PFS, overall PFS, OS, and the incidence of hepatic function deterioration of these four groups. The best clinical outcomes were achieved by group 1 (with PTV $\leq 279 \mathrm{~cm}^{3}$ and NTNL-V $\mathrm{V}_{\text {BED20 }} \leq 40.8 \%$ ), while the worst outcomes were observed in group 4 (with PTV $>279 \mathrm{~cm}^{3}$ and

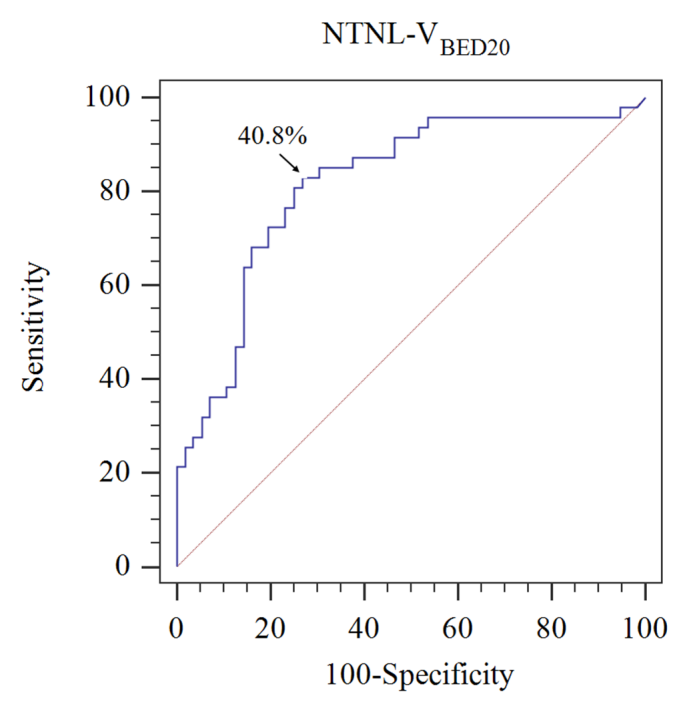

(B)

Figure 1: The receiver operating characteristic curves. A. PTV associated with hepatic function deterioration, and B. NTNL- $\mathrm{V}_{\text {BED20 }}$ associated with hepatic function deterioration 
PTV

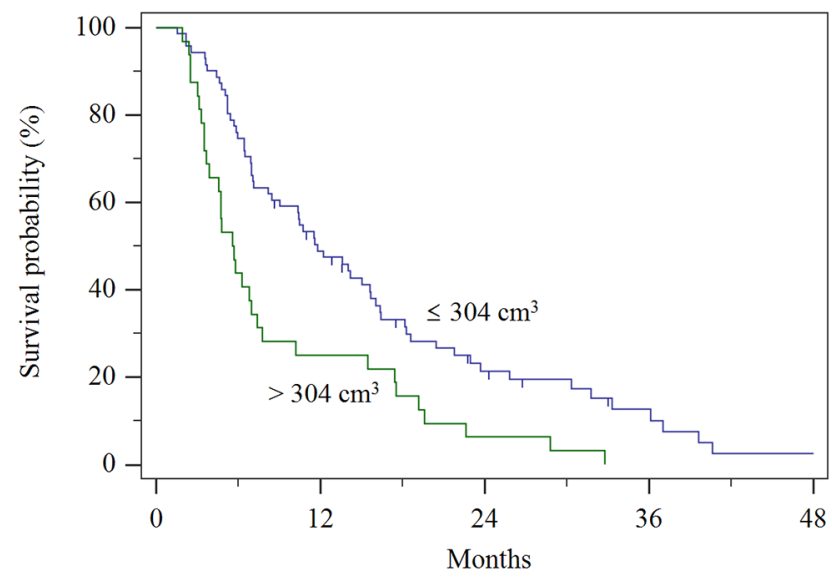

(A)
Total dose (BED)

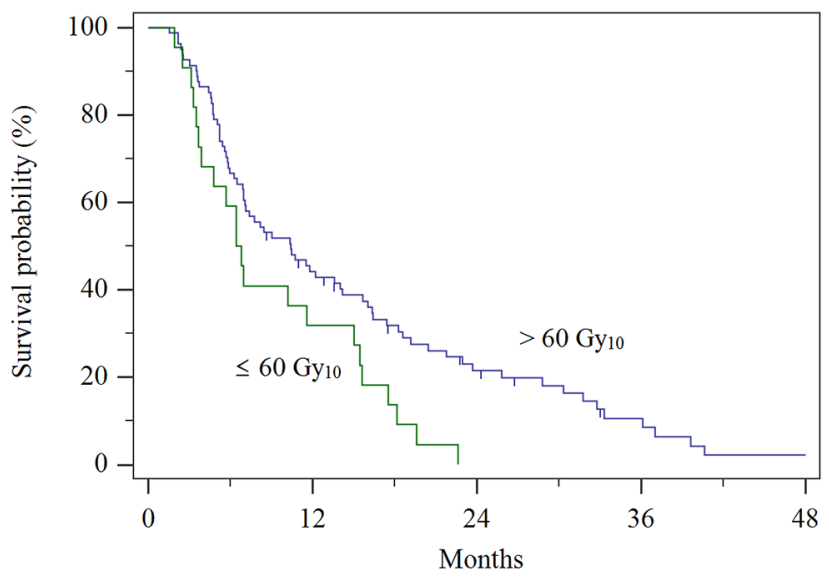

(B)

Figure 2: Local progression-free survival curve. A. according to PTV, and B. according to total dose (BED)

Table 1: Clinical outcomes in four groups associated with hepatic function deterioration and local progression-free survival

(A) Comparison of four groups associated with hepatic function deterioration

\begin{tabular}{|c|c|c|c|c|c|}
\hline Variables & Group 1 & Group 2 & Group 3 & Group 4 & \multirow{3}{*}{$p$ value } \\
\hline $\operatorname{PTV}\left(\mathrm{cm}^{3}\right)$ & $\leq 279$ & $\leq 279$ & $>279$ & $>279$ & \\
\hline NTNL-V ${ }_{\text {BED20 }}(\%)$ & $\leq 40.8$ & $>40.8$ & $\leq 40.8$ & $>40.8$ & \\
\hline \multicolumn{6}{|l|}{ Outcome } \\
\hline No of patients & 38 & 31 & 12 & 22 & \\
\hline Local PFS (mo) & 15.7 & 6.9 & 6.3 & 5.6 & 0.007 \\
\hline Overall PFS (mo) & 7.9 & 6.4 & 4.5 & 4.7 & 0.115 \\
\hline OS (mo) & 15.8 & 16.1 & 8.3 & 4.5 & 0.057 \\
\hline $\begin{array}{l}\text { Deterioration of } \\
\text { hepatic function }(\%)\end{array}$ & 2.6 & 52.6 & 66.7 & 81.8 & $<0.001$ \\
\hline
\end{tabular}

(B) Comparison of four groups associated with local progression-free survival

\begin{tabular}{|c|c|c|c|c|c|}
\hline Variables & Group A & Group B & Group C & Group D & \multirow{3}{*}{$p$ value } \\
\hline $\operatorname{PTV}\left(\mathrm{cm}^{3}\right)$ & $\leq 304$ & $\leq 304$ & $>304$ & $>304$ & \\
\hline Total dose $\left(\mathrm{Gy}_{10}\right)$ & $>60$ & $\leq 60$ & $>60$ & $\leq 60$ & \\
\hline \multicolumn{6}{|l|}{ Outcome } \\
\hline No of patients & 65 & 6 & 14 & 18 & \\
\hline Local PFS (mo) & 11.8 & 11.6 & 5.7 & 4.8 & 0.005 \\
\hline Overall PFS (mo) & 7.7 & 5.6 & 4.8 & 4.6 & 0.055 \\
\hline OS (mo) & 16.0 & 11.6 & 7.4 & 6.8 & 0.009 \\
\hline $\begin{array}{l}\text { Deterioration of } \\
\text { hepatic function }(\%)\end{array}$ & 30.7 & 50.0 & 71.4 & 77.8 & $<0.001$ \\
\hline
\end{tabular}

Abbreviations: PTV = planning target volume; NTNL = non-target normal liver; BED = biologically effective dose;

No = number; PFS = progression-free survival; mo = months; OS = overall survival 
NTNL- $\mathrm{V}_{\text {BED20 }}>40.8 \%$ ). The differences in median local PFS, overall PFS, OS, and incidence of hepatic function deterioration between group 1 and group 4 were 10.1 months, 3.2 months, 11.3 months, and $79.2 \%$, respectively ( $p=0.007,0.115,0.057$, and $<0.001$, respectively).

In addition, patients were divided in four groups (group A, B, C, and D) based on a PTV of $304 \mathrm{~cm}^{3}$ and a total dose of $60 \mathrm{~Gy}_{10}$, which were identified as cut-off values of significant radiotherapeutic parameters associated with local PFS. Table 1(B) shows local PFS, overall PFS, OS, and incidence of hepatic function deterioration in these four groups. The best clinical outcomes were achieved by patients in group A (with PTV $\leq 304 \mathrm{~cm}^{3}$ and total dose $>60 \mathrm{~Gy}_{10}$ ) and the worst outcomes were observed in group D (with PTV $>304 \mathrm{~cm}^{3}$ and total dose $\leq 60 \mathrm{~Gy}_{10}$ ). The differences in median local PFS, overall PFS, OS, and incidence of hepatic function deterioration between group A and group D were 7.0 months, 3.1 months, 9.2 months, and $47.1 \%$, respectively ( $p=0.005,0.055,0.009$, and $<0.001$, respectively).

Based on these results, we merged group 1 and group A in a favorable prognosis group (with PTV $\leq 279 \mathrm{~cm}^{3}$, total dose $>60 \mathrm{~Gy}_{10}$ and NTNL-V $\mathrm{BED} 20 \leq 40.8 \%$ ), while group 4 and group D formed an unfavorable group (with $40 \%$ ) as an unfavorable group. These groups were compared with respect to local PFS, overall PFS, OS, and incidence of hepatic function deterioration (Table 2, Figure 3). The differences in median local PFS, overall PFS, OS, and incidence of hepatic function deterioration between the favorable prognosis group and unfavorable prognosis group were 11.2 months, 3.6 months,

Table 2: Comparison between the favorable and unfavorable prognosis groups

\begin{tabular}{|c|c|c|c|}
\hline Variables & Favorable prognosis group & Unfavorable prognosis group & \multirow{4}{*}{$p$ value } \\
\hline $\operatorname{PTV}\left(\mathrm{cm}^{3}\right)$ & $\leq 279$ & $>304$ & \\
\hline Total dose $\left(\mathrm{Gy}_{10}\right)$ & $>60$ & $\leq 60$ & \\
\hline NTNL-V ${ }_{\text {BED20 }}(\%)$ & $\leq 40.8$ & $>40.8$ & \\
\hline \multicolumn{4}{|l|}{ Outcome } \\
\hline No of patients & 30 & 12 & \\
\hline Local PFS (mo) & 16.0 & 4.8 & $<0.001$ \\
\hline Overall PFS (mo) & 7.9 & 4.3 & 0.022 \\
\hline $\mathrm{OS}(\mathrm{mo})$ & 17.9 & 6.8 & $<0.001$ \\
\hline $\begin{array}{l}\text { Deterioration of } \\
\text { hepatic function }(\%)\end{array}$ & 3.3 & 75 & $<0.001$ \\
\hline
\end{tabular}

Abbreviations: PTV = planning target volume; NTNL = non-target normal liver; BED = biologically effective dose; No $=$ number; PFS = progression-free survival; mo = months; OS = overall survival

Local PFS

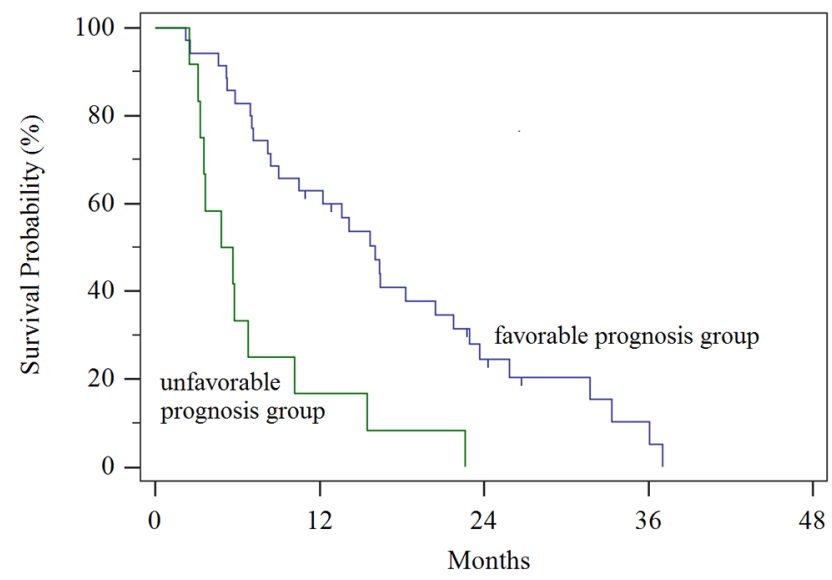

(A)
OS

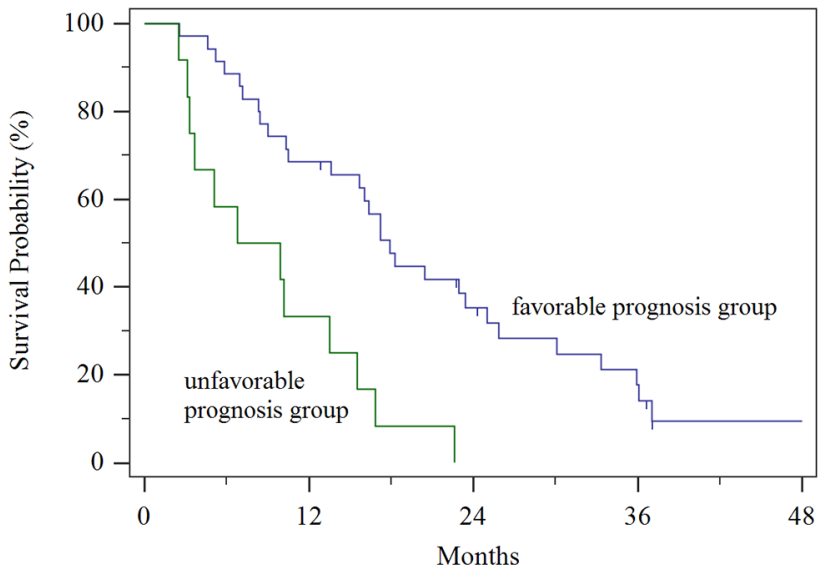

(B)

Figure 3: Local progression-free survival and overall survival of the favorable and unfavorable prognosis groups. A. local progression-free survival, and B. overall survival 
11.1 months, and $71.7 \%$, respectively ( $p<0.001,0.0215$, $<0.001$, and $<0.001$, respectively).

\section{DISCUSSION}

Although the therapeutic role of RT in unresectable locally advanced HCC has not been well established, many studies have reported that it is safe and effective for the treatment of HCC patients [5-9, 13-17]. Because the improved gain of survival cannot be achieved in all patients received RT, it is important to establish the optimal criteria of radiotherapeutic parameters in order to improve its efficacy. Therefore, we attempted to identify the optimal cut-off values of radiotherapeutic parameters associated with local PFS and hepatic function deterioration to enhance its safety and efficacy. Among the possible prognostic factors, we excluded the pretreatment ChildPugh (CP) score because only patients with a pretreatment CP score of 5-7 were considered to be eligible for RT. A PTV of $304 \mathrm{~cm}^{3}$ and a total dose of $60 \mathrm{~Gy}_{10}$ were found to be cut-off values of significant radiotheraprutic parameters associated with local PFS, and a PTV of $279 \mathrm{~cm}^{3}$ and a NTNL-V ${ }_{\text {BED20 }}$ of $40.8 \%$ were found to be cut-off values of significant radiotheraprutic parameters associated with hepatic function deterioration. Based on the values of these three parameters, a favorable and an unfavorable prognosis group were defined and compared. Local PFS, overall PFS, OS, and incidence of hepatic function deterioration were all better in the favorable prognosis group than that in the unfavorable prognosis group (local PFS: 16.0 vs. 4.8 months; overall PFS: 7.9 vs. 4.3 months; OS: 17.9 vs. 6.8 months; incidence of hepatic function deterioration: $3.3 \%$ vs. $75.0 \%$ ). Our results demonstrated that optimizing the selection of patients for RT resulted in an improvement in both its safety and efficacy.

Dawson et al. reported that the best outcomes after 3-dimensional conformal radiotherapy (3D-CRT) or stereotactic body radiotherapy (SBRT) are achieved in patients with fewer than 3 lesions that are less than $6 \mathrm{~cm}$ in size with intact liver function [18]. Similary, Toramatsu et al. found that when the nominal diameter of gross tumor volume (GTV) is more than $6.3 \mathrm{~cm}$, the average risk of radiation-induced liver disease is $94.5 \%$ for intensitymodulated radiotherapy (IMRT) [19]. As for SBRT, the optimal tumor size for RT is smaller. Takeda et al. recommended combination therapy of TACE plus SBRT for solitary tumors with a tumor volume less than $100 \mathrm{cc}$ [20]. Huang et al. found that OS is significantly lower in patients with tumors larger than $4 \mathrm{~cm}$ (HR: $0.5, p=0.028$ ) [21]. The PTV of $279 \mathrm{~cm}^{3}$ and $304 \mathrm{~cm}^{3}$ found in this study are comparable with the GTV of about $6.5-7 \mathrm{~cm}$ diameter, which is larger than the $4-5.5 \mathrm{~cm}$ diameter of tumor that is recommended for SBRT, and with the GTV of $6.3 \mathrm{~cm}$ recommended by Toramatsu et al. [19]. Chen et al. reported that a higher dose ( $>50$ Gy in 2 Gy fractions) resulted in better survival (median OS, 10.5 vs. 6.9 months, $p<0.001$ )
[22]. A biologically effective dose (BED) of $60 \mathrm{~Gy}_{10}$, which was also identified as a significant parameter in this study, corresponds to $50 \mathrm{~Gy}$ in 2 Gy fractions. A dose of 45-50 Gy or higher in conventional fractionations has generally been used in the 3D-CRT studies, while 30-60 Gy in 3-5 fractions, similar to or higher than a BED of $60 \mathrm{~Gy}_{10}$, has been used in the SBRT studies. Consistently, a BED of $60 \mathrm{~Gy}_{10}$ in this study was considered the minimum dose required to achieve a better local PFS. The NTNL$\mathrm{V}_{\mathrm{BED} 20}$ was a significant parameter associated with hepatic function deterioration, which was identified in our previous study [23]. Liang et al. suggested that $\mathrm{V}_{20}$ is an important parameter in patients treated with hypofractionated RT (4-6 Gy per fraction) [24], and Son et al. demonstrated that $V_{15}$ is a significant parameter associated with increased CP score [25]. When compared with $\mathrm{V}_{20}$ of $48.5 \%$ reported by Liang et al. and $\mathrm{V}_{15}$ of $43.2 \%$ reported by Son et al., the $\mathrm{V}_{\mathrm{BED} 20}$ of $40.8 \%$ found in this study could be considered adequate. Our toxicity results support the validity of this cut-off value as there was a large difference in the incidence of hepatic function deterioration between the favorable and unfavorable prognosis group $(3.3 \%$ vs. $75.0 \%)$.

In addition, the values of these parameters are not fixed but can be varied in the treatment planning phase. The parameters in this study were derived from tomotherapy. When other treatment planning techniques, such as 3D-CRT and fixed-beam IMRT, are used, the distribution of low-to-moderate dose could differ from that when tomotherapy is used; moreover, the distribution of low-to-moderate dose in other treatments could affect the value of these parameters. Therefore, PTV, total dose, and NTNL- $\mathrm{V}_{\text {BED20 }}$ all depend on the treatment techniques. The use of compression devices, gated therapy, or imageguided radiotherapy (IGRT) for reducing respiratoryinduced tumor motion or allowing a more precise delivery of radiation could allow a smaller PTV to be used. The radiation dose and NTNL- $\mathrm{V}_{\mathrm{BED} 20}$ could also be improved by using the IG-IMRT technique instead of 3D-CRT. The values of these three parameters could be adjusted within the favorable ranges during the treatment planning.

In conclusion, we suggest that the optimal criteria of radiotherapeutic parameters for patients with unresectable locally advanced $\mathrm{HCC}$ are: PTV $\leq 279 \mathrm{~cm}^{3}$, total dose $>60 \mathrm{~Gy}_{10}$ and NTNL-V $\mathrm{BED} 20 \leq 40.8 \%$. Because patients who meet these criteria would derive the most benefit from RT, the addition of RT to current standard modalities should be considered. Further confirmation of these findings should be sought in larger-scale studies.

\section{MATERIALS AND METHODS}

\section{Patients}

The inclusion criteria were: primary unresectable locally advanced HCC without distant metastasis, RT with a curative aim, age $>18$ years, $\mathrm{CP}$ score of 5,6 , or 7 
within 1 month prior to RT, Eastern Cooperative Oncology Group (ECOG) performance status of 0 or 1 .

A total of 103 patients were eligible for this study, all of whom received RT using the TomoTherapy Hi-Art system (TomoTherapy Inc., Madison, WI, USA), at Incheon St. Mary's Hospital and Seoul St. Mary's Hospital, between March 2006 and February 2012. Patient data were retrospectively reviewed following institutional review board approval.

Age, sex, ECOG performance status, TNM stage, pretreatment CP score, absence or presence of hepatitis or liver cirrhosis, and level of alpha-fetoprotein (AFP) were evaluated. Prior to RT, TACE was performed in 95 patients (median, 2 times; range, 1-11 times), percutaneous ethanol injection (PEI) in 8 patients (median, 2 times; range, 1-3 times), radiofrequency ablation (RFA) in 8 patients (median, 2 times; range, 1-3 times), and systemic chemotherapy in 14 patients. The patient characteristics are shown in Table 3.

\section{Radiotherapy}

For simulation, patients were immobilized using the BodyFix system (Medical Intelligence $\mathrm{GmbH}$, Schwabmunchen, Germany), in which the abdomen was compressed at low pressure using foil. A spiral computed tomography (CT) scan was then performed with intravenous contrast and a $2.5 \mathrm{~mm}$ slice thickness, using either a SOMATOM (Siemens, Berlin, Germany) or a LightSpeed RT16 (GE, Waukesha, WI, USA) CT scanner.

The GTV was defined as the tumor volume enhanced in the arterial phase and diluted in the delayed phase of the CT scan. The PTV was generated by adding 5-15 $\mathrm{mm}$ to the GTV in 71 of the 103 patients, facilitating asymmetric margin expansion in order to reduce irradiation to the stomach, duodenum, and small intestine. In the remaining 32 patients, 4-dimensional (4D) CT was performed to generate the internal target volume in order to compensate for respiration-induced liver movement due to the installation of 4D-CT in March 2009 at Seoul St. Mary's Hospital and in March 2011 at Incheon St. Mary's Hospital. Organs at risk, such as the total liver, NTNL, stomach, duodenum, intestine, kidney, and spinal cord, were also contoured for evaluation of the irradiated dose. The NTNL volume was defined as the total liver volume minus the PTV.

The PTV was $330.1 \pm 275.1 \mathrm{~cm}^{3}$, and the normal liver volume was $1209.7 \pm 426.9 \mathrm{~cm}^{3}$. The dose per fraction to the PTV was 1.8-5 Gy, and the total dose was 40-60 Gy (median: $50 \mathrm{~Gy}$ ), prescribed to $95 \%$ of the PTV. Forty-one patients $(39.8 \%)$ were treated with 1.8-2.5 Gy per fraction, while 62 patients $(60.2 \%)$ were treated with 4-5 Gy per fraction. The total dose delivered to the target was converted to a BED, based on the linearquadratic model with an $\alpha / \beta$ ratio of 10 , and the total dose was $50.5-82.5 \mathrm{~Gy}_{10}$ (median: $73.5 \mathrm{~Gy}_{10}$ ). The $\alpha / \beta$ ratio of the normal liver is unclear. In our previous study, we determined the $\alpha / \beta$ ratio of the normal liver by comparing the incidence of hepatic function deterioration between 2 different fractionation schemes of RT [23]. Therefore, an $\alpha / \beta$ ratio of 8 was used for calculating the BED of the normal liver in this study. NTNL- $\mathrm{V}_{\mathrm{BED} 20}$, which is the fraction of the NTNL volume receiving more than a BED of $20 \mathrm{~Gy}_{8}$, was identified as a predictive parameter for hepatic function deterioration [23]. NTNL-V $\mathrm{BED}_{\text {BE }}$ was 10.6-79.3\% (median: 45.4\%).

Treatment planning utilized the built-in software of the TomoTherapy Planning Station, which was used for the TomoTherapy Hi-Art system. We evaluated the dose-volume histogram and the dose distributions slice by slice. We then approved the treatment plan if the tumor coverage was adequate and the doses to the surrounding normal tissues were within acceptable limits. Megavoltage cone-beam CT was performed during each treatment session before actual beam delivery. The patient set-up and position were corrected using automated image registration, and the anatomical accuracy was always evaluated by a radiation oncologist.

\section{Evaluation and statistical analysis}

Tumor response was defined as the best response in the dynamic CT scans obtained 1 month and 3 months after RT, according to the modified Response Evaluation Criteria in Solid Tumors [27]. PFS was measured from the date of RT to the date of progression or the last follow-up. OS was measured from the date of RT to the date of death or the last follow-up.

We considered local PFS and hepatic function deterioration as clinically relevant responses to RT. Hepatic function deterioration was defined as an increase of at least 2 points in the CP score within 3 months after completing RT. An increase in the $\mathrm{CP}$ score reflects hepatic function deterioration, and this increase has been used for the assessment of hepatic toxicity after treatment for liver diseases [23, 25-28].

We evaluated the PTV, NTNL- $\mathrm{V}_{\text {BED20, }}$, and total dose $\left(\mathrm{Gy}_{10}\right)$ as significant parameters affecting the hepatic function. Maximally selected chi-square test was used for evaluating PTV, NTNL- $\mathrm{V}_{\text {BED20 }}$, and total dose $\left(\mathrm{Gy}_{10}\right)$ and identifing their cut-off values. The results were re-evaluated by using a ROC curve. We also evaluated PTV and total dose $\left(\mathrm{Gy}_{10}\right)$ as significant parameters affecting local PFS. The cut-off values were calculated using maximally selected log-rank test and the results were re-evaluated with the Cox regression model and Kaplan-Meier survival analysis.

Based on these results, patients were divided in four groups according to the cut-off values of radiotherapeutic parameters associated with local PFS or hepatic function deterioration, respectively, and local PFS, overall PFS, 
Table 3: Clinical characteristics

\begin{tabular}{|c|c|c|}
\hline Variables & $n$ & $(\%)$ \\
\hline \multicolumn{3}{|l|}{ Gender } \\
\hline Male & 80 & 77.7 \\
\hline Female & 23 & 22.3 \\
\hline \multicolumn{3}{|l|}{ Age (year) } \\
\hline median & 59 & \\
\hline range & $21-80$ & \\
\hline \multicolumn{3}{|l|}{ ECOG } \\
\hline 0 & 38 & 36.9 \\
\hline 1 & 65 & 63.1 \\
\hline \multicolumn{3}{|l|}{ Hepatitis } \\
\hline None & 2 & 1.9 \\
\hline $\mathrm{HBV}$ & 73 & 70.9 \\
\hline $\mathrm{HCV}$ & 9 & 8.7 \\
\hline Others & 19 & 18.4 \\
\hline \multicolumn{3}{|l|}{ Liver cirrhosis } \\
\hline No & 32 & 31.1 \\
\hline Yes & 71 & 68.9 \\
\hline \multicolumn{3}{|l|}{ AFP (IU/mL) } \\
\hline$\leq 400$ & 67 & 65.0 \\
\hline$>400$ & 36 & 35.0 \\
\hline \multicolumn{3}{|c|}{ Child-Pugh score before RT } \\
\hline A5 & 61 & 59.2 \\
\hline A6 & 30 & 29.1 \\
\hline B7 & 12 & 11.7 \\
\hline \multicolumn{3}{|l|}{ TNM stage } \\
\hline II & 14 & 13.6 \\
\hline III & 81 & 78.6 \\
\hline IVA & 8 & 7.8 \\
\hline \multicolumn{3}{|c|}{ Previous treatment } \\
\hline None & 7 & 6.8 \\
\hline TACE & 95 & 92.2 \\
\hline RFA & 8 & 7.8 \\
\hline PEI & 8 & 7.8 \\
\hline Chemotherapy & 14 & 13.6 \\
\hline
\end{tabular}

Abbreviations: ECOG PS = Eastern Cooperative Oncology Group performance status; $\mathrm{HBV}=$ hepatitis $B$ virus; $\mathrm{HCV}=$ hepatitis $\mathrm{C}$ virus; $\mathrm{PVTT}=$ portal vein tumor thrombosis; $\mathrm{AFP}=$ alpha-fetoprotein; $\mathrm{TACE}=$ transcarterial chemoembolization; $\mathrm{RFA}=$ radiofrequency ablation; $\mathrm{PEI}=$ percutaneous ethanol injection
OS and incidence of hepatic function deterioration were compared. Then, by combination of these groups, patients were finally divided in two groups, with either favorable or unfavorable prognosis group, and these two groups were then compared in terms of local PFS, overall PFS, $\mathrm{OS}$, and incidence of hepatic function deterioration.

Statistical analysis was performed using $\mathrm{R}$ version 3.1.2 (R Development Core Team, Vienna, Austria) and MedCalc version 14.12 (MedCalc Software bvba, Ostend, Belgium), and $p$ values $<0.05$ were considered to be statistically significant.

\section{CONFLICTS OF INTEREST}

The authors declare that they have no competing interests.

\section{REFERENCES}

1. Llovet JM, Bruix J. Systematic review of randomized trials for unresectable hepatocellular carcinoma: Chemoembolization improves survival. Hepatology. 2003; 37:429-442.

2. Lo CM, Ngan H, Tso WK, Liu CL, Lam CM, Poon RT, Fan ST, Wong J. Randomized controlled trial of transarterial lipiodol chemoembolization for unresectable hepatocellular carcinoma. Hepatology. 2002; 35:1164-1171.

3. Jiang W, Zeng ZC. Is it time to adopt external beam radiotherapy in the NCCN guidelines as a therapeutic strategy for intermediate/advanced hepatocellular carcinoma?. Oncology. 2013; 84:69-74.

4. Chia-Hsien Cheng J, Chuang VP, Cheng SH, Lin YM, Cheng TI, Yang PS, Jian JJ, You DL, Horng CF, Huang AT. Unresectable hepatocellular carcinoma treated with radiotherapy and/or chemoembolization. Int J Cancer. 2001; 96:243-252.

5. Guo WJ, Yu EX, Liu LM, Li J, Chen Z, Lin JH, Meng ZQ, Feng Y. Comparison between chemoembolization combined with radiotherapy and chemoembolization alone for large hepatocellular carcinoma. World J Gastroenterol: WJG. 2003; 9:1697-1701.

6. Lee IJ, Seong J. Radiotherapeutic strategies in the management of hepatocellular carcinoma. Oncology. 2011; 81:123-133.

7. Shim SJ, Seong J, Han KH, Chon CY, Suh CO, Lee JT. Local radiotherapy as a complement to incomplete transcatheter arterial chemoembolization in locally advanced hepatocellular carcinoma. Liver Int. 2005; 25:1189-1196.

8. Yasuda $\mathrm{S}$, Ito $\mathrm{H}$, Yoshikawa $\mathrm{M}$, Shinozaki $\mathrm{M}$, Goto N, Fujimoto H, Nasu K, Uno T, Itami J, Isobe K, Shigematsu N, Ebara M, Saisho H. Radiotherapy for large hepatocellular carcinoma combined with transcatheter arterial embolization and percutaneous ethanol injection therapy. Int J Oncol. 1999; 15:467-473. 
9. Zeng ZC, Tang ZY, Fan J, Zhou J, Qin LX, Ye SL, Sun HC, Wang BL, Yu Y, Wang JH, Guo W. A comparison of chemoembolization combination with and without radiotherapy for unresectable hepatocellular carcinoma. Cancer J. 2004; 10:307-316.

10. Cheng AL, Guan Z, Chen Z, Tsao CJ, Qin S, Kim JS, Yang TS, Tak WY, Pan H, Yu S, Xu J, Fang F, Zou J, Lentini G, Voliotis D, Kang YK. Efficacy and safety of sorafenib in patients with advanced hepatocellular carcinoma according to baseline status: subset analyses of the phase III Sorafenib Asia-Pacific trial. Eur J Cancer. 2012; 48:1452-1465.

11. Llovet JM, Ricci S, Mazzaferro V, Hilgard P, Gane E, Blanc JF, de Oliveira AC, Santoro A, Raoul JL, Forner A, Schwartz M, Porta C, Zeuzem S, Bolondi L, Greten TF, Galle PR, et al. Sorafenib in advanced hepatocellular carcinoma. N Eng J Med. 2008; 359:378-390.

12. Kim DY, Park W, Lim DH, Lee JH, Yoo BC, Paik SW, Kho KC, Kim TH, Ahn YC, Huh SJ. Three-dimensional conformal radiotherapy for portal vein thrombosis of hepatocellular carcinoma. Cancer. 2005; 103:2419-2426.

13. Yoon SM, Lim YS, Won HJ, Kim JH, Kim KM, Lee HC, Chung YH, Lee YS, Lee SG, Park JH, Suh DJ. Radiotherapy plus transarterial chemoembolization for hepatocellular carcinoma invading the portal vein: longterm patient outcomes. Int J Radiat Oncol Biol Phys. 2012; 82:2004-2011.

14. Nakazawa T, Adachi S, Kitano M, Isobe Y, Kokubu S, Hidaka H, Ono K, Okuwaki Y, Watanabe M, Shibuya A, Saigenji K. Potential prognostic benefits of radiotherapy as an initial treatment for patients with unresectable advanced hepatocellular carcinoma with invasion to intrahepatic large vessels. Oncology. 2007; 73:90-97.

15. Toya R, Murakami R, Baba Y, Nishimura R, Morishita S, Ikeda O, Kawanaka K, Beppu T, Sugiyama S, Sakamoto T, Yamashita Y, Oya N. Conformal radiation therapy for portal vein tumor thrombosis of hepatocellular carcinoma. Radiother Oncol. 2007; 84:266-271.

16. Yamada K, Izaki K, Sugimoto K, Mayahara H, Morita Y, Yoden E, Matsumoto S, Soejima T, Sugimura K. Prospective trial of combined transcatheter arterial chemoembolization and three-dimensional conformal radiotherapy for portal vein tumor thrombus in patients with unresectable hepatocellular carcinoma. Int J Radiat Oncol Biol Phys. 2003; 57:113-119.

17. Zeng ZC, Fan J, Tang ZY, Zhou J, Qin LX, Wang JH, Sun HC, Wang BL, Zhang JY, Jiang GL, Wang YQ. A comparison of treatment combinations with and without radiotherapy for hepatocellular carcinoma with portal vein and/or inferior vena cava tumor thrombus. Int J Radiat Oncol Biol Phys. 2005; 61:432-443.

18. Dawson LA. Overview: Where does radiation therapy fit in the spectrum of liver cancer local-regional therapies? Semin Radiat Oncol. 2011; 21:241-246.
19. Toramatsu C, Katoh N, Shimizu S, Nihongi H, Matsuura T, Takao S, Miyamoto N, Suzuki R, Sutherland K, Kinoshita R, Onimaru R, Ishikawa M, Umegaki K, Shirato H. What is the appropriate size criterion for proton radiotherapy for hepatocellular carcinoma? A dosimetric comparison of spot-scanning proton therapy versus intensity-modulated radiation therapy. Radiat Oncol. 2013; 8:48.

20. Takeda A, Takahashi M, Kunieda E, Takeda T, Sanuki N, Koike Y, Atsukawa K, Ohashi T, Saito H, Shigematsu N, Kubo A. Hypofractionated stereotactic radiotherapy with and without transarterial chemoembolization for small hepatocellular carcinoma not eligible for other ablation therapies: Preliminary results for efficacy and toxicity. Hepatol Res. 2008; 38:60-69.

21. Huang WY, Jen YM, Lee MS, Chang LP, Chen CM, Ko KH, Lin KT, Lin JC, Chao HL, Lin CS, Su YF, Fan CY, Chang YW. Stereotactic body radiation therapy in recurrent hepatocellular carcinoma. Int J Radiat Oncol Biol Phys. 2012; 84:355-361.

22. Chen YX, Zeng ZC, Fan J, Tang ZY, Zhou J, Zeng MS, Zhang JY, Sun J. Defining prognostic factors of survival after external beam radiotherapy treatment of hepatocellular carcinoma with lymph node metastases. Clin Transl Oncol. 2013; 15:732-740.

23. Son SH, Jang HS, Lee H, Choi BO, Kang YN, Jang JW, Yoon SK, Kay CS. Determination of the alpha/beta ratio for the normal liver on the basis of radiation-induced hepatic toxicities in patients with hepatocellular carcinoma. Radiat Oncol. 2013; 8:61.

24. Liang SX, Huang XB, Zhu XD, Zhang WD, Cai L, Huang HZ, Li YF, Chen L, Liu MZ. Dosimetric predictor identification for radiation-induced liver disease after hypofractionated conformal radiotherapy for primary liver carcinoma patients with Child-Pugh Grade A cirrhosis. Radiother Oncol. 2011; 98:265-269.

25. Son SH, Kay CS, Song JH, Lee SW, Choi BO, Kang YN, Jang JW, Yoon SK, Jang HS. Dosimetric parameter predicting the deterioration of hepatic function after helical tomotherapy in patients with unresectable locally advanced hepatocellular carcinoma. Radiat Oncol. 2013; 8:11.

26. Liaw YF, Sung JJ, Chow WC, Farrell G, Lee CZ, Yuen H, Tanwandee T, Tao QM, Shue K, Keene ON, Dixon JS, Gray DF, Sabbat J. Lamivudine for patients with chronic hepatitis B and advanced liver disease. N Eng J Med. 2004; 351:1521-1531.

27. Son SH, Jang HS, Jo IY, Choi BO, Jang JW, Yoon SK, Kay CS. Significance of an increase in the Child-Pugh score after radiotherapy in patients with unresectable hepatocellular carcinoma. Radiat Oncol. 2014; 9:101.

28. Yu JI, Park HC, Lim do H, Park WY. Predictive factors for Child-Pugh score elevation in hepatocellular carcinoma patients treated with conformal radiation therapy: dosevolume histogram analysis. Tumori. 2013; 99:164-171. 